\title{
A Stable Nanoporous Silicon Anode Prepared by Modified
}

\section{Magnesiothermic Reactions}

\author{
Xiaolin Li, ${ }^{1}$ Pengfei Yan, ${ }^{1}$ Bruce W Arey, ${ }^{1}$ Wei Luo, ${ }^{2}$ Xiulei $\mathrm{Ji}^{2}{ }^{2}$ Chongmin Wang ${ }^{1}$ \\ Jun Liu, ${ }^{1 *}$ Ji-Guang Zhang ${ }^{1 *}$ \\ 1. Pacific Northwest National Laboratory, Richland, Washington, 99352 \\ 2. Department of Chemistry, Oregon State University, Corvallis, OR, 97331
}

*Corresponding authors. Tel.: +1 5093726515 or +1 5093754443. Email address:

jiguang.zhang@pnnl.gov (J.-G. Zhang) or jun.liu@pnnl.gov (J. Liu)

\begin{abstract}
Porous silicon prepared by low-cost and scalable magnesiothermic reactions is a promising anode material for Li-ion batteries; yet, retaining good cycling stability for such materials in electrodes of practical loading remains a challenge. Here, we engineered the nanoporous silicon from a modified magnesiothermic reaction by controlled surface oxidization forming a $<5 \mathrm{~nm}$ oxide layer on the 10 to 20 $\mathrm{nm}$ Si nanocrystallites. High loading electrodes of $\sim 3 \mathrm{mAh} / \mathrm{cm}^{2}$ demonstrates stable cycling with $\sim 80 \%$ capacity retention over 150 cycles. The specific discharge capacity based on the total electrode weight is $\sim 1,000 \mathrm{mAh} / \mathrm{g}$ at the lithiation/delithiation current density of $0.5 / 0.75 \mathrm{~mA} / \mathrm{cm}^{2}$. This work reveals the importance of the surface treatment on nanostructured Si, which will lead to a well-controlled ratio of silicon and surface oxide layer and provide guidance on further improvement on silicon-based anode materials.
\end{abstract}

Keywords: silicon anode, lithium ion batteries, magnesiothermic reaction, porous silicon 


\section{Introduction}

Silicon (Si) has $\sim 10$ times theoretical specific capacity of graphite and is one of the most promising anode for Li-ion batteries used in long range electrical vehicles.[1] However, practical use of Si is largely limited by both the unsatisfactory electrochemical performance and challenges associated with the high manufacture cost and poor scalability. Si materials experienced large volume expansion and contraction under lithiation and delithiation, which leads to pulverization of large Si particles (> $200 \mathrm{~nm}$ ) and subsequent loss of electrical contact, repeated breaking/formation of solid electrolyte interphase (SEI) and continuous consumption of electrolyte.[1-4] As a result, Si electrodes, especially at high mass loading, exhibit rapid capacity fade upon electrochemical cycling. There has been tremendous effort on understanding and mitigation of the capacity fading using nanostructured Si materials including the synthesis of ultra-fine Si nanoparticles $(<50 \mathrm{~nm})$, surface coating, development of new binders, and design of novel nanostructured Si materials such as nanowires, nanotubes, hollow spheres, and coreshell structures.[5-41] Recently, pomegranate-like Si-C yolk-shell structures have demonstrated over 100 stable cycles at high loading Si electrodes.[32] Porous Si and Si-based composites with the preengineered void space to accommodate the volume change of Si and a surface coating layer to minimize the electrolyte decomposition and stabilize the SEI layer, can have limited apparent volume change of Si particles and greatly improved electrochemical performance Si anode even at relatively high loading.[13, 23-29, 32-34, 36] Recently, porous Si prepared by electrochemical etching also demonstrates good longterm cycling stability at high Si loading conditions.[33] Electrodes of high area-specific-capacity of $\sim 1.5$ $\mathrm{mAh} / \mathrm{cm}^{2}$ and $3 \mathrm{mAh} / \mathrm{cm}^{2}$ demonstrated $\sim 92 \%$ capacity over 300 cycles and $\sim 90 \%$ capacity retention over 100 cycles, respectively. Micro-sized porous Si obtained from the disproportionation reaction of SiO was composited with engineered graphene wrap or nonfilling carbon coating and demonstrated stable performance over 100 cycles at an area-specific-capacity $3 \mathrm{mAh} / \mathrm{cm}^{2} .[29,34,36]$ However, scalable low 
cost production of porous Si materials with good long term cycling stability at high mass loading remains a significant challenge.

Magnesiothermic reaction (MR) is a well-known low-cost and scalable approach for the production of Si materials. Since 2007, various kinds of Si nanostructures including nanocrystals, nanotubes, nanowires, and porous films have been synthesized using MR with different silica precursors. [25, 27, 35, 37-47] Yet, because of the exothermic nature of the MR, the local reaction temperature is much higher than the set temperature and hence results in great difficulty in controlling the nano structure of the produced Si. Recently, a modified MR with the use of heat scavenger has demonstrated good control on the local reaction temperature and subsequent nano-structure of Si product.[48] Porous silicon spheres or nanowires prepared by the method demonstrated good performance as Li-ion battery anodes.[40, 41] In this study, we engineered the porous Si by modified MR with controlled surface oxidization and demonstrated its good performance as stable high loading Li-ion battery anodes. The engineered porous Si has a surface oxide coating layer of $\sim 2$ to $5 \mathrm{~nm}$ on the Si nanocrystallites of $\sim 10$ to $20 \mathrm{~nm}$. High loading electrodes of $\sim 3 \mathrm{mAh} / \mathrm{cm}^{2}$ area-specific-capacity demonstrates stable cycling with $\sim 80 \%$ capacity retention over 150 cycles, similar to the porous Si from anodization. The specific discharge capacity based on the total electrode weight is $\sim 1,000 \mathrm{mAh} / \mathrm{g}$ at the lithiation/delithiation current density of 0.5/0.75 $\mathrm{mA} / \mathrm{cm}^{2}$. These results suggest that stable bulk $\mathrm{Si}$ anode materials from low cost scalable production are possible even at deep lithiation and high loading conditions required for practical applications.

\section{Material and methods}

\section{Synthesis}

Magnesiothermic porous Si was prepared via a modified reaction with $\mathrm{NaCl}$ as the thermal scavenger.[48] Diatom with the size of $\sim 10$ micron was dispersed to an aqueous $\mathrm{NaCl}$ solution under stirring at room temperature (Silica/ $\mathrm{NaCl}: 1 / 10$ in weight). The mixture was heated to $60^{\circ} \mathrm{C}$ under 
vigorous stirring followed by drying under vacuum at $150^{\circ} \mathrm{C}$ to remove water. Dried diatom $/ \mathrm{NaCl}$ powder (11 g) and 0.9g Mg powder was ground together under an Ar atmosphere and then sealed in a Swagelok ${ }^{\circledR}$ reactor. Then, the diatom/ $\mathrm{NaCl} / \mathrm{Mg}$ mixture was heated in a tube furnace at $650^{\circ} \mathrm{C}$ for $2.5 \mathrm{~h}$ under an Ar atmosphere. After cooling to room temperature, the obtained products were first immersed in a $\mathrm{H}_{2} \mathrm{O} / \mathrm{EtOH}$ solution, where $\mathrm{NaCl}$ can be recycled by drying the filtrate. Then, $1 \mathrm{M} \mathrm{HCl}$ and $5 \%$ aqueous $\mathrm{HF}$ were used to remove $\mathrm{MgO}$ and excess diatom precursor, respectively. Finally, the products were collected, washed with $\mathrm{EtOH}$, and vacuum-dried at $60^{\circ} \mathrm{C}$ overnight. Surface oxidization of the magnesiothermic porous Si was carried out by calcining the sample in a box furnace in air at $500^{\circ} \mathrm{C}$ for $1 \mathrm{hr}$

Electrochemical etched porous Si was prepared according to the procedure reported before[33] by electrochemical etching of heavily boron-doped, $<100>$ oriented single crystal Si wafers $(<1 \mathrm{~m} \Omega \cdot \mathrm{cm}$ resistivity, Siltronix Inc.) by application of a constant current density of $\sim 225 \mathrm{~mA} / \mathrm{cm}^{2}$ for $358 \mathrm{~s}$ in an aqueous $48 \%$ hydrofluoric acid (HF)/ethanol electrolyte (HF: EtOH = 3:1, v: v). A freestanding film of the MSS was then removed from the crystalline Si substrate by application of a constant current density of $\sim 10 \mathrm{~mA} / \mathrm{cm}^{2}$ for $750 \mathrm{~s}$ in an aqueous HF/ethanol electrolyte (HF: EtOH = 1:30, v: v). The film was washed several times with ethanol, then fractured by ultrasonication in ethanol to form $\sim 40-\mu \mathrm{m}$ particles, and dried for further use.

Carbon coating was conducted using a vacuum CVD system. The MSS sample was loaded in a tube furnace, which then was evacuated at room temperature to a vacuum level of $\leq 1$ mTorr. The furnace was heated to $600^{\circ} \mathrm{C}$ at a rate of $10^{\circ} \mathrm{C} / \mathrm{min}$, and when at $600^{\circ} \mathrm{C}$, the precursor gas (argon: acetylene $=$ 9:1) was introduced. The furnace temperature was increased to $690^{\circ} \mathrm{C}$ and maintained at that temperature for $30 \mathrm{~min}$. After carbon deposition, the furnace was cooled to room temperature in pure argon.

\section{Characterization}


XRD spectra were obtained on a Philips X'Pert X-ray diffractometer using a $\mathrm{Cu} \mathrm{K}_{\alpha}$ sealed tube $(\lambda=$ $1.54178 \AA$ A) at $0.5^{\circ} / \mathrm{min}$. SEM measurement were conducted on an FEI Helios Nanolab dual-beam focused ion beam scanning electron microscope (FIB/SEM). After cycling, the samples were obtained from disassembled cells, washed three times with anhydrous diethyl carbonate, and dried in the antechamber of the glove box under vacuum. TEM and HRTEM measurements were performed using an FEI Titan 80300 microscope operating at an accelerating voltage of $300 \mathrm{kV}$.

\section{Electrochemical measurement}

The electrode was prepared by mixing an appropriate amount of the carbon-coated porous Si sample with Super P (Timcal), and carboxymethyl cellulose sodium salt (Na-CMC, Sigma Aldrich) in distilled water to form a slurry, which was then pasted on a copper foil (Pred. Materials International, Inc.). The Si loading in the mixture was kept at $\sim 50 \mathrm{wt} \%$. The binder of $\mathrm{Na}-\mathrm{CMC}$ was kept at $20 \mathrm{wt} \%$ in all electrodes. After drying in vacuum at $70^{\circ} \mathrm{C}$, the electrodes were tested in coin cells with Li metal as the counter and the reference electrode. The electrolyte was 1M LiPF6 in a mixture of ethylene carbonate and diethyl carbonate in a 1:1 weight ratio with 10 wt\% fluorinated ethylene carbonate as electrolyte additive. A microporous membrane (Celgard 3501) was used as the separator. The coin cells were assembled in an argon-filled glove box (MBraun Inc.). All the batteries were tested using galvanostatic charge-discharge protocols on a BT-2000 Arbin Battery Testing System (Arbin Instruments) at room temperature. All tests were conducted within a voltage range of 0.005 to $1.0 \mathrm{~V}$. The batteries were cycled at a current density of $0.06 \mathrm{~mA} / \mathrm{cm}^{2}$ for three cycles and then cycled at $0.75 \mathrm{~mA} / \mathrm{cm}^{2}$ for charge (de-lithiation) and $0.5 \mathrm{~mA} / \mathrm{cm}^{2}$ for discharge (lithiation). All of the specific weight-capacity values calculated in this work were based on the whole electrode weight including active material, binder and conductive carbon.

\section{Results and discussion}


Porous Si sample was synthesized by a modified MR method with $\mathrm{NaCl}$ as the heat scavenger to retain Si nanocrystallites.[48] Then the sample was heated in air at $500^{\circ} \mathrm{C}$ for $1 \mathrm{hr}$ to have the surface engineered with a layer of silicon oxide (EPSi-mag). The morphology, porous structure, crystallization, and surface treatment details of EPSi-mag are characterized by scanning electron microscopy (SEM), transmission electron microscopy (TEM), and X-ray diffraction (XRD). Figure $1 \mathrm{a}$ and $1 \mathrm{~b}$ show typical SEM images of the EPSi-mag at different magnifications. The EPSi-mag has the morphology and structure similar to the diatom precursor and the porous Si after the magnesiothermic reaction (PSi-mag).[47] The size of EPSi-mag secondary particles is similar to PSi-mag of $\sim 10 \mu \mathrm{m}$. Large micron-sized pores co-exist with the small mesopores formed by the aggregation of Si nanoparticles (Figures 1a and 1b). TEM study shows that the porous Si has a three-dimensional network structure with uniform particles of 10 to 20 $\mathrm{nm}$ surrounding mesopores of $\sim 10 \mathrm{~nm}$ (Figure 1c). It is believed that the surface oxidization is at very mild condition and has little effect to the morphology or porous structure. Figure $1 \mathrm{~d}$ shows the X-ray diffraction (XRD) patterns of porous Si before and after surface oxidization. EPSi-mag remains highly crystalline structure similar to those of PSi-mag. Yet, a weak broad feature around $24^{\circ}$ was observed in the XRD indicating the formation of amorphous oxide.

High resolution TEM was used to characterize the detail surface structure of the nanoporous Si before and after surface oxidization. Representative images of PSi-mag and EPSi-mag are shown in Figure 2. Both samples are highly crystallized Si nanoparticles with the domain size of $\sim 10 \mathrm{~nm}$ randomly attached together (Figures $2 \mathrm{a}$ and $2 \mathrm{~b}$ ). Before surface oxidization, there is barely any oxide layer at the surface of Si nanocrystallites (Figure 2a) for PSi-mag. Yet, an amorphous layer is clearly observed on the surface of EPSi-mag nano-Si (Figures 2b), consistent with the broad amorphous feature in the XRD pattern (Figure 1d). The amorphous layer is silicon oxide formed during the oxidization treatment in air. It has a controlled thickness of $\sim 2$ to $5 \mathrm{~nm}$, indicated by the arrow in Figures $2 \mathrm{~b}$. This thin oxide layer 
may slightly lower the capacity and induce first-cycle irreversible capacity loss, yet it will help to improve the cycling stability (vide infra).

PSi-mag and EPSi-mag were coated with amorphous carbon using chemical vapor deposition (CVD) [49] and used to prepare electrodes for battery test. The function of carbon coating is three folds: First, it improves the conductivity of the porous Si sample; second, it helps to mechanically/electrically integrate the particle during cycling; third, it mitigates the exposure of Si surface and hence alleviates electrolyte decomposition. As a control sample, porous Si by anodic electrochemical etching (Mesoporous Si Sponge (MSS)) was prepared according to the procedure developed before [33] and tested at same conditions as those used to test PSi-mag and EPSi-mag.

Nanoporous Si with controlled surface oxidization shows largely improved cycling stability comparing to the as-synthesized PSi-mag (Figures 3 and 4). The cycling stability actually is similar to those of MSS at high specific areal capacities of $\sim 3 \mathrm{mAh} / \mathrm{cm}^{2}$ (Figures S1 and S2). Figure 3 shows the electrochemical performance of high loading PSi-mag and EPSi-mag electrodes with areal capacity of $\sim 3 \mathrm{mAh} / \mathrm{cm}^{2}$ at 0.5 $\mathrm{mA} / \mathrm{cm}^{2}$ discharge and $0.75 \mathrm{~mA} / \mathrm{cm}^{2}$ charge current density. The capacity retention for PSi-mag over 150 cycles is $\sim 69.5 \%$ (Figure 3a). While after surface oxidization, the EPSi-mag retained $\sim 78 \%$ capacity over 150 cycles (Figure 3b), which is almost the same as those of MSS electrode at similar loading ( $80 \%$ capacity retention over 150 cycles (Figure S1)). Figure 3C shows the charge-discharge curves of PSi-mag and EPSi-mag at the $1^{\text {st }}, 4^{\text {th }}$ and $150^{\text {th }}$ cycle. The charge-discharge curves of these porous Si materials prepared by MR obtained between $0.005 \mathrm{~V}$ and $1.0 \mathrm{~V}$ are similar to those of MSS and other porous Si materials.[25, 27, 33, 35, 37-41] Comparing with PSi-mag, a relatively large irreversible capacity loss occurred for EPSi-mag during the first cycle, which is related to the surface oxide layer and consistent with the amorphous signal appearing at $2 \theta=24^{\circ}$ in the XRD pattern (Figure 1d). Figure $3 \mathrm{~d}$ shows the specific capacity fading with cycling for PSi-mag and EPSi-mag. The initial specific discharge capacity at $0.5 \mathrm{~mA} / \mathrm{cm}^{2}$ decreases from $\sim 1,250 \mathrm{mAh} / \mathrm{g}$ to $~ 1,000 \mathrm{mAh} / \mathrm{g}$ after the surface oxidization treatment for 
PSi-mag. In spite of that, the specific capacity and first cycle Coulombic efficiency of EPSi-mag are still higher than that of MSS by $\sim 250 \mathrm{mAh} / \mathrm{g}$ and $\sim 7 \%$, respectively (Figure S1). The specific capacity values reported in this work are based on the weight of the full electrode, including the Si active material, binder, and carbon additive.

To further corroborate the good cycling stability of EPSi-mag, thick EPSi-mag electrodes of $\sim 3$ $\mathrm{mAh} / \mathrm{cm}^{2}$ are tested at low charge/discharge current density. Figure 4 presents the typical cycling performance of an EPSi-mag electrode at $\sim 0.06 \mathrm{~mA} / \mathrm{cm}^{2}$ charge/discharge current density. The capacity retention over 100 cycles is $\sim 84 \%$ and the corresponding specific capacity is $\sim 1,150$ for EPSi-mag (Figure 4a). The cycling stability of EPSi-mag is better than PSi-mag and MSS. PSi-mag electrode has 76\% capacity retention over 100 cycles at a low charge/discharge current density of $\sim 0.06 \mathrm{~mA} / \mathrm{cm}^{2}$ while the capacity retention of MSS is $\sim 79 \%$ over 100 cycles (Figure S2). It should be noted that the cells were under cycling for about a year because of the low current density. However, in spite of the slow charge/discharge rate $(0.02 \mathrm{C})$ and long cycle time ( 1 year), the Coulombic efficiency for EPSi-mag during the long term cycles is stabled at $\sim 99.2 \%$, indicating extremely low side reaction rate between the engineered Si anode and electrolyte.

Cycled EPSi-mag and PSi-mag electrodes were analyzed to better understand the electrode evolution and capacity fading mechanism. The battery was dis-assembled after 100 cycles and the electrode at delithiated state was collected and washed with diethyl carbonate thoroughly for SEM investigation. Figure S3a shows that the electrode surface was covered with a layer of SEI while the structure of electrode remains similar to the fresh electrode (Figure S3b) without any active material peeling off. The cycled PSi-mag electrode, however, showed cracks on the electrode surface, indicating damage of the electrode and hence faster capacity fade after long term cycling (Figure S3c). This is consistent with better capacity retention of EPSi-mag anode as compared to PSi-mag anode shown in Fig. 3. 
The porosity is not the reason for EPSi-mag to have a better performance than PSi-mag. The EPSi-mag has reduced surface area $\left(\sim 150 \mathrm{~m}^{2} / \mathrm{g}\right)$ and porosity $\left(0.52 \mathrm{~cm}^{3} / \mathrm{g}\right)$ comparable to those of as-prepared PSimag ( $295 \mathrm{~m}^{2} / \mathrm{g}$ and $\left.1.2 \mathrm{~cm}^{3} / \mathrm{g}\right)$. However, the porosity of EPSi-mag is still more than twice of those previously reported porous Si anodes from magnesiothermic reactions $\left(\sim 0.2 \mathrm{~cm}^{3} / \mathrm{g}\right) \cdot[25,27,35,37-48]$ This high porosity is sufficient in accommodating the volume change of EPSi-mag. Furthermore, the heat scavenger introduced in the synthesis of PSi-mag keeps the reaction at a medium temperature and hence the Si nanocrystallites obtained are uniform with the size of $<50 \mathrm{~nm}$. [48] The controlled surface oxidization is a more efficient way to form a dense surface oxide layer than storage in ambient condition for a long time. This oxide layer, similar to the clamping effect reported for Si nanotubes,[10] leads to improved cycling stability of EPSi-mag.

Based on the above discussion, the good cycling stability of the EPSi-mag electrodes can be attributed to several factors: 1 ) the pores in the EPSi-mag material is sufficient to serve as buffers to accommodate the volume expansion of $\mathrm{Si}$ during lithiation; 2) the $\sim 10 \mathrm{~nm}$ Si nanocrystallites are small enough to expand/shrink reversibly during lithiation/de-lithiation without breaking; $[2,3,5] 3)$ the solid surface oxide layer formed at the pore wall surface confines/ reinforces the nanostructure;[10] and 4) the carbon coating not only improves the electric conductivity and mechanical integrity the particle, but also mitigates the exposure of Si surface and hence alleviates electrolyte decomposition.

It is believed that all these four factors are indispensable and work synergistically resulting in the good electrochemical performance of Si anodes. Si has $300 \%$ change in volume upon full lithiation. In order to limit volume change in outside dimension of particles and in the thickness of the full electrode, it is desired to have large pore diameter that can accommodate large volume change and small $\mathrm{Si}$ nanocrystallites that has small displacements. In material design for practical batteries, it is important that the pore size and the size of Si nanocrystallites to be well balanced so that they can be sufficient to accommodate the volume change of $\mathrm{Si}$, but also avoid waste of space which will decrease the volumetric 
energy density of the batteries. The importance of the surface oxide layer is clearly demonstrated by the fact that the cycling stability is greatly improved after well controlled surface oxidization. The enhancement on the cycling stability of the Si anode is not obvious if the oxide layer is too thin. While too thick an oxide layer causes decreases in specific capacity and first cycle Coulombic efficiency. In case that the oxidation temperature increased to more than $800^{\circ} \mathrm{C}$, the porous Si structure of EPSi-mag will be damaged and the cell impedance will increase rapidly. We also found that the carbon coating should be thick enough to improve the mechanical integrity of EPSi-mag and withstand the stress generated from the Si volume change and mitigate electrolyte decomposition. This is consistent with the recent observation on dual carbon coating with graphene or coating with thick carbon shell.[21, 34, 36] Therefore, a well-controlled oxidation process and optimized carbon coating is critical for enhance cycling stability of nano-Si (EPSi-mag) structure prepared in this work.

It has to be noted that the porous Si electrodes have a low first cycle Coulombic efficiency because of the nanometer scale Si particle size, large surface area and the surface oxide layer. This could be a problem in practical full-cell batteries. Prelithiation with lithium powder ${ }^{33}$ or other approaches are under development to address the challenge of low first cycle Coulombic efficiency.

\section{Conclusion}

In summary, the nanoporous Si prepared by modified magnesiothermic reaction with surface engineering (both oxidation and carbon coating) exhibit good cycling stability at high specific areal capacity of $\sim 3 \mathrm{mAh} / \mathrm{cm}^{2}$ required for practical applications. It paves a way to use stable bulk Si anode materials from economical and scalable production as high capacity, stable anode materials in the next generation Li-ion batteries.

\section{Acknowledgements}

This work was supported by the Assistant Secretary for Energy Efficiency and Renewable Energy, Office of Vehicle Technologies of the U.S. Department of Energy under Contract No. DE-AC02- 
05CH11231, Subcontract No. 18769 under the under the Advanced Battery Materials Research (BMR) program. A portion of the research was performed in the Environmental Molecular Sciences Laboratory, a national scientific user facility sponsored by the Department of Energy's Office of Biological and Environmental Research and located at Pacific Northwest National Laboratory.

\section{Appendix A. Supporting information}

Supplementary data associated with this article can be found in the online version. 


\section{References}

[1] U. Kasavajjula, C. S. Wang, A. J. Appleby, J. Power Sources 163 (2007), 1003-1039.

[2] X. H. Liu, L. Zhong, S. Huang, S. X. Mao, T. Zhu, J. Y. Huang, ACS Nano 2 (2012), 1522-1531.

[3] M. T. McDowell, I. Ryu, S. W. Lee, C. M. Wang, W. D. Nix, Y. Cui, Adv. Mater. 24 (2012), 60346041.

[4] M. Gu, Y. Li, X. L. Li, S. Y. Hu, X. W. Zhang, W. Xu, S. Thevuthasan, D. R. Baer, J. G. Zhang, J. Liu, C. M. Wang, ACS Nano 6 (2012), 8439-8447.

[5] H. J. Kim, M. Seo, M.-H. Park, J. Cho, Angew. Chem. Int. Ed. 49 (2010), 2146-2149.

[6] I. Kovalenko, B. Zdyrko, A. Magasinski, B. Hertzberg, Z. Milicev, R. Burtovyy, I. Luzinov, G. Yushin, Science 334 (2011), 75-79.

[7] G. Liu, S. D. Xun, N. Vukmirovic, X. Y. Song, P. Olalde-Velasco, H. H. Zheng, V. S. Battaglia, L. W. Wang, W. L. Yang, Adv. Mater. 23 (2011), 4679-4683.

[8] D. M. Piper, J. J. Travis, M. Young, S.-B. Son, S. C. Kim, K. H. Oh, S. M. George, C. M. Ban, S.-H. Lee, Adv. Mater. 26 (2014), 1596-1601.

[9] C. K. Chan, H. L. Peng, G. Liu, K. Mcilwrath, X. F. Zhang, R. A. Guggins, Y. Cui, Nature Nanotech. 3 (2008), 31-35.

[10] H. Wu, G. Chan, J. W. Choi, I. Ryu, Y. Yao, M. T. McDowell, S. W. Lee, A. Jackson, Y. Yang, L. B. Hu, Y. Cui, Nature Nanotech. 7 (2012), 310-315.

[11] Y. Yao, M. T. McDowell, I. Ryu, H. Wu, N. Liu, L. B. Hu, W. D. Nix, Y. Cui, Nano Lett. 11 (2011), 2949-2954.

[12] H. Wu, G. Y. Zheng, N. Liu, T. J. Carney, Y. Yang, Y. Cui, Nano Lett. 12 (2012), 904-906.

[13] A. Magasinki, P. Dixon, B. Hertzberg, A. Kvit, J. Ayala, G. Yushin, Nature Mater. 9 (2010), 353358. 
[14] X. L. Li, P. Meduri, X. L. Chen, W. Qi, M. H. Engelhard, W. Xu, F. Ding, J. Xiao, W. Wang, C. M. Wang, J. G. Zhang, J. Liu, J. Mater. Chem. 22 (2012), 11014-11017.

[15] X. L. Chen, X. L. Li, F. Ding, W. Xu, J. Xiao, Y. L. Cao, P. Meduri, J. Liu, G. L. Graff, J. G. Zhang, Nano Lett. 12 (2012), 4124-4130.

[16] M. H. Park, M. G. Kim, J. Joo, K. Kim, J. Y. Kim, S. h. Ahn, Y. Cui, J. Cho, Nano Lett. 9 (2009), 38443847.

[17] T. Song, J. L. Xia, J.-H. Lee, D. H. Lee, M.-S. Kwon, J.-M. Choi, J. Wu, S. K. Doo, H. Chang, W. I. Park, D. S. Zang, H. S. Kim, Y. G. Huang, K.-C. Hwang, J. A. Rogers, U. Y. Park, Nano Lett. 10 (2010), 1710-1716.

[18] K. Evanoff, A. Magasinski, J. B. Yang, G. Yushin, Adv. Energy Mater. 1 (2011), 495-498.

[19] M. Y. Ge, J. P. Rong, X. Fang, C. W. Zhou, Nano Lett. 12 (2012), 2318-2323.

[20] Y. S. Hu, R. Demir-Cakan, M. M. Titirici, J. O. Muller, R. Schlogl, M. Antonietti, J. Maier, Angew. Chem. Int. Ed. 47 (2008), 1645-1649.

[21] T. H. Hwang, Y. M. Lee, B. S. Kong, J. S. Seo, J. W. Choi, Nano Lett. 12 (2012), 802-807.

[22] X. Zhao, C. M. Hayner, M. C. Kung, H. H. Kung, Adv. Energy Mater. 1 (2011), 1079-1084.

[23] H. J. Kim, B. H. Han, J. B. Choo, J. Cho, Angew. Chem. Int. Ed. 47 (2008), 10151-10154.

[24] B. M. Bang, J. I. Lee, H. J. Kim, J. Cho, S. J. Park, Adv. Energy Mater. 2 (2012), 878-883.

[25] D. Y. Chen, X. Mei, G. Ji, M. H. Lu, J. P. Xie, J. M. Lu, J. Y. Lee, Angew. Chem. Int. Ed. 51 (2012), 2409-2413.

[26] S. R. Gowda, V. Pushparaj, S. Herle, G. Girishkumar, J. G. Gordon, H. Gullapalli, X. B. Zhan, P. M. Ajayan, A. L. M. Reddy, Nano Lett. 12 (2012), 6060-6065.

[27] H. P. Jia, P. F. Gao, J. Yang, J. L. Wang, Y. N. Nuli, Z. Yang, Adv. Energy Mater. 1 (2011), 10361039.

[28] M. Thakur, S. L. Sinsabaugh, M. J. Isaacson, M. S. Wong, S. L. Biswal, Sci. Rep. 2 (2012), 795. 
[29] R. Yi, F. Dai, M. L. Gordin, S. R. Chen, D. H. Wang, Adv. Energy Mater. 3 (2013), 295-300.

[30] H. G. Zhang, P. V. Braun, Nano Lett. 12 (2012), 2778-2783.

[31] H. Wu, G. H. Yu, L. J. Pan, N. Liu, M. T. McDowell, Z. N. Bao, Y. Cui, Nat. Commun. 4 (2013), 1943.

[32] N. Liu, Z. D. Lu, J. Zhao, M. T. McDowell, H.-W. Lee, W. T. Zhao, Y. Cui, Nature Nanotech. 9 (2014), 187-192.

[33] X. L. Li, M. Gu, S. Y. Hu, R. Kennard, P. F. Yan, X. L. Chen, C. M. Wang, M. J. Sailor, J. G. Zhang, J. Liu, Nat. Commun. 5 (2014), 5105.

[34] R. Yi, J. T. Zai, F. Dai, M. L. Gordin, D. H. Wang, Nano Energy 6 (2014), 211-218.

[35] R. Y. Zhang, Y. J. Du, D. Li, D. K. Shen, J. P. Yang, Z. P. Guo, H. K. Liu, A. A. Elzatahry, D. Y. Zhao, Adv. Mater. 26 (2014), 6749-6755.

[36] Z. D. Lu, N. Liu, H.-W. Lee, J. Zhao, W. Y. Li, Y. Z. Li, Y. Cui, ACS Nano 9 (2015), 2540-2547.

[37] J. K. Yoo, J. Kim, Y. S. Jung, K. Kang, Adv. Mater. 24 (2012), 5452-5456.

[38] Y. Yu, L. Gu, C. B. Zhu, S. Tsukimoto, P. A. V. Aken, J. Maier, Adv. Mater. 22 (2010), 2247-2250.

[39] K. H. Kim, D. J. Lee, K. M. Cho, S. J. Kim, J.-K. Park, H.-T. Jung, Sci. Rep. 5 (2015), 9014.

[40] W. Wang, Z. Favors, R. Lonescu, R. Ye, H. H. Bay, M. Ozkan, C. Ozkan, Sci. Rep. 5 (2015), 8781.

[41] Z. Favors, H. H. Bay, Z. Mutlu, K. Ahmed, R. Lonescu, R. Ye, M. Ozkan, C. Ozkan, Sci. Rep. 5 (2015), 8246.

[42] Z. H. Bao, M. R. Weatherspoon, S. Shian, Y. Cai, P. D. Graham, S. M. Allan, G. Ahmad, M. B. Dickerson, B. C. Church, Z. T. Kang, H. W. Abernathy III, C. J. Summers, M. L. Liu, K. H. Sandhage, Nature 446 (2007), 172-175.

[43] E. K. Richman, C. B. Kang, T. Brezesinski, S. H. Tolbert, Nano Lett. 8 (2008), 3075-3079.

[44] F. Gallego-Gomez, M. Ibisate, D. Golmayo, F. J. Palomares, M. Herrera, J. Hernandez, S. I. Molina, A. Blanco, C. Lopez, Adv. Mater. 23 (2011), 5219-5223.

[45] C. Y. Khripin, D. Pristinski, D. R. Dunphy, C. J. Brinker, B. Kaehr, ACS Nano 5 (2011), 1401-1409. 
[46] Y. Zhang, J. Huang, J. Mater. Chem. 21 (2011), 7161-7165.

[47] N. Liu, K. F. Huo, M. T. McDowell, J. Zhao, Y. Cui, Sci. Rep. 3 (2013), 1919.

[48] W. Luo, X. F. Wang, C. Meyers, N. Wannenmacher, W. Sirisaksoontorn, M. M. Lerner, X. L. Ji, Sci. Rep. 3 (2013), 2222.

[49] J. Salonen, E. Laine, L. Niinisto, J. Appl. Phys. 91 (2002), 456-461. 


\section{Figure captions}

Figure 1. Structure characterization of the EPSi-mag. a) and b) SEM images of the EPSi-mag at different magnifications. c) TEM image of the EPSi-mag. d) XRD patterns of EPSi-mag compared with assynthesized PSi-mag.

Figure 2. Surface structure of porous Si before and after oxidization treatment. a) High resolution TEM image PSi-mag. b) High resolution TEM image EPSi-mag.

Figure 3. Electrochemical performance of typical PSi-mag and EPSi-mag electrodes of $\sim 3 \mathrm{mAh} / \mathrm{cm}^{2}$. a) Cycling performance of PSi-mag. b) Cycling performance of EPSi-mag. c) Charge/discharge curves of the PSi-mag and EPsi-mag electrodes in a) and b) at the $1^{\text {st }}, 4^{\text {th }}$ and $150^{\text {th }}$ cycle. d) Specific capacities of the PSi-mag and EPsi-mag electrodes in a) and b).

Figure 4. Electrochemical performance of EPSi-mag electrodes at a low charge/discharge current density of $\sim 0.06 \mathrm{~mA} / \mathrm{cm}^{2}$. a) Cycling performance a representative EPSi-mag electrodes of $\sim 3 \mathrm{mAh} / \mathrm{cm}^{2}$. b) Coulombic efficiency of the EPSi-mag electrodes in a). Inset of b) is the Coulombic efficiency from $2^{\text {nd }}$ to $100^{\text {th }}$ cycle. 
Figure 1
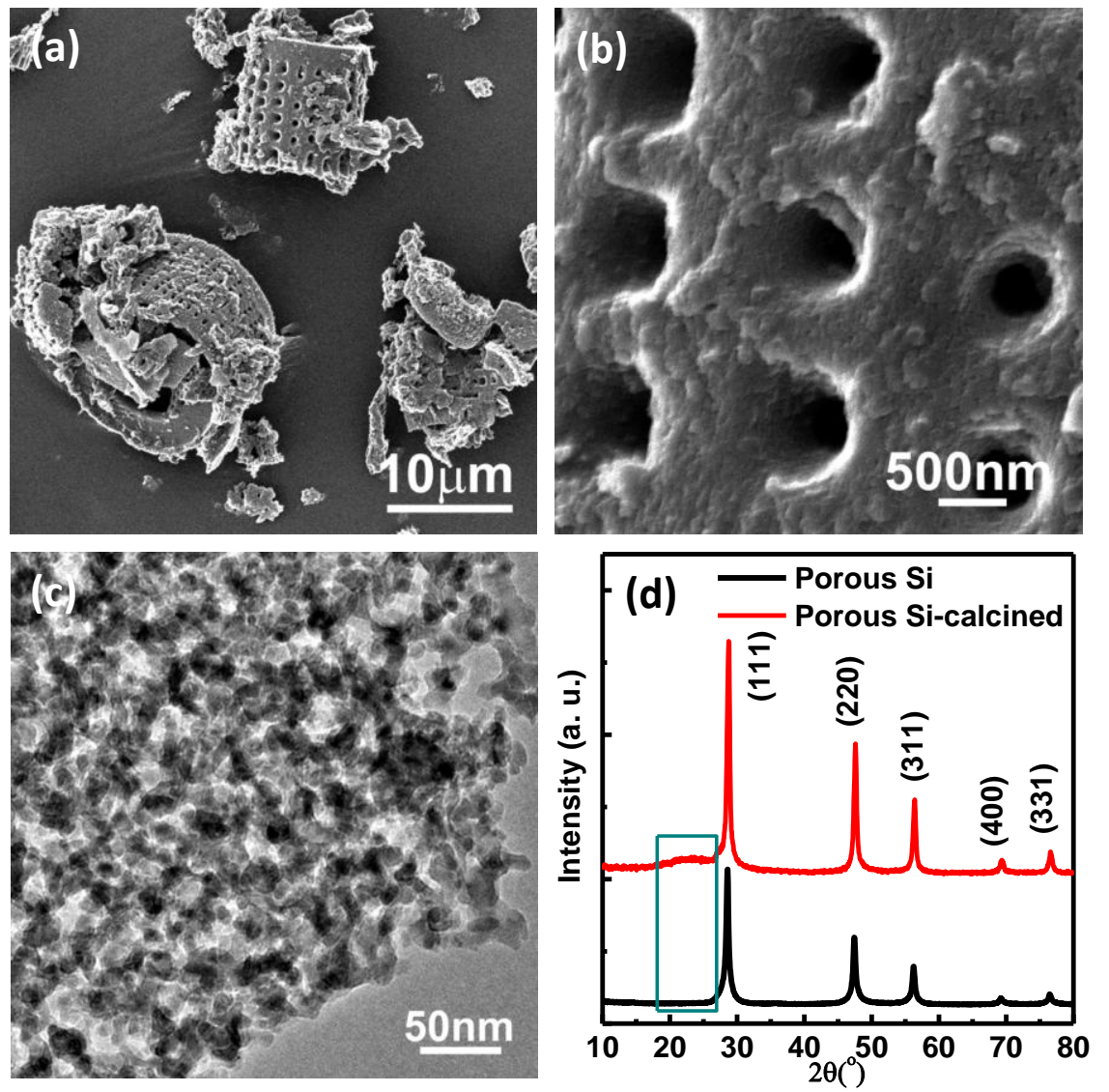
Figure 2
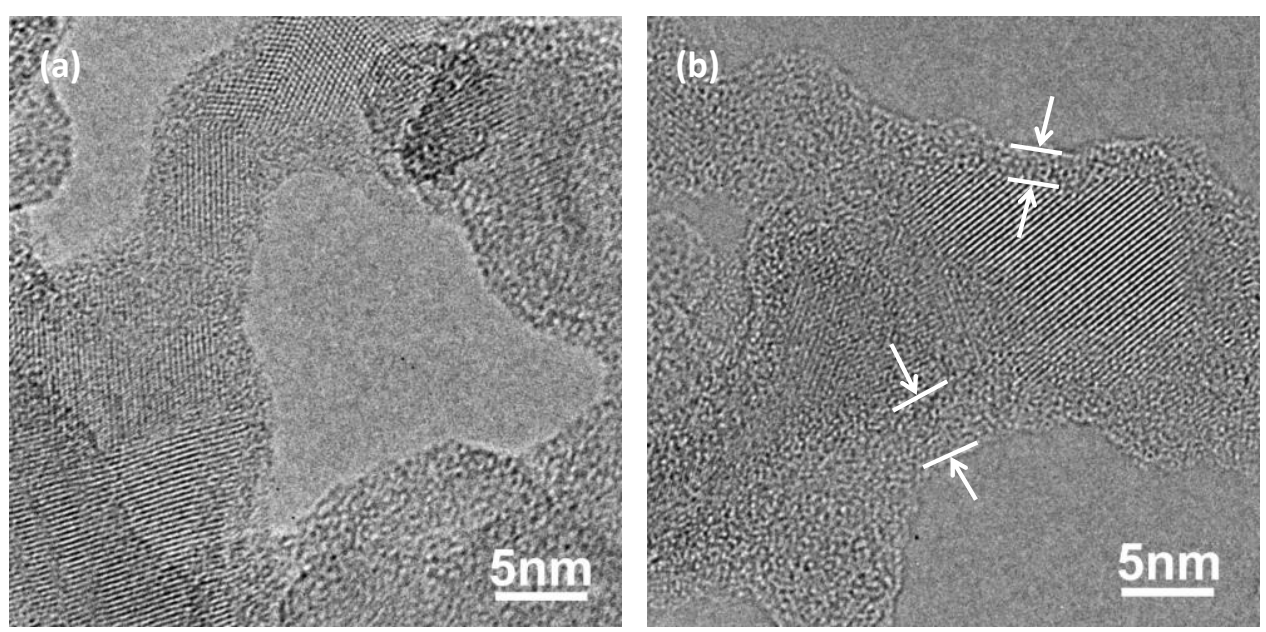
Figure 3

(a)

(c)
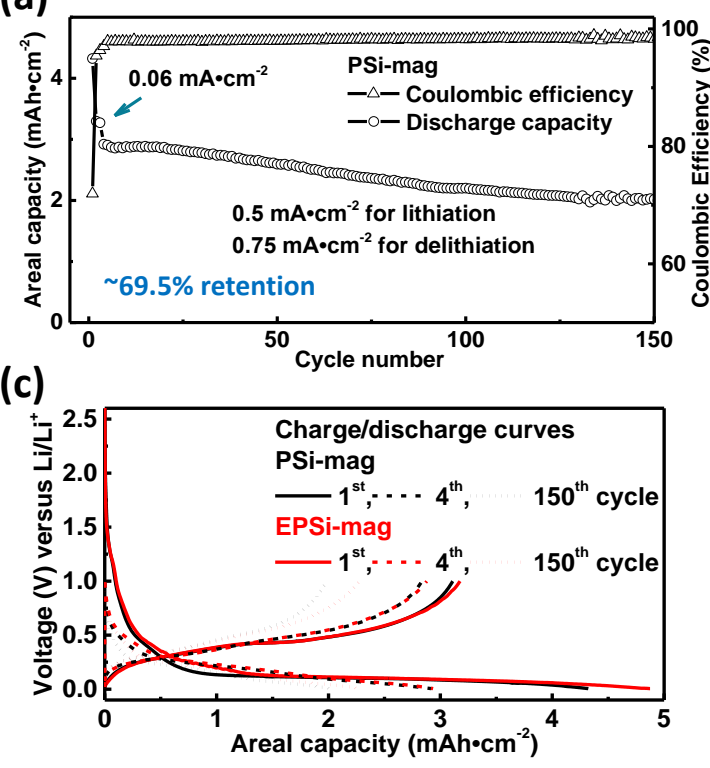

(b)

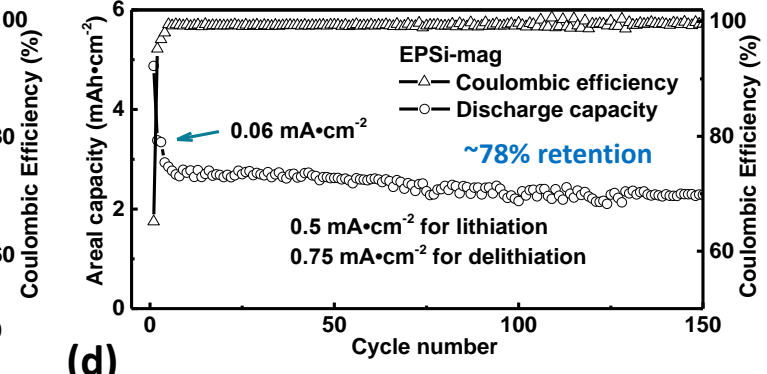

(d)

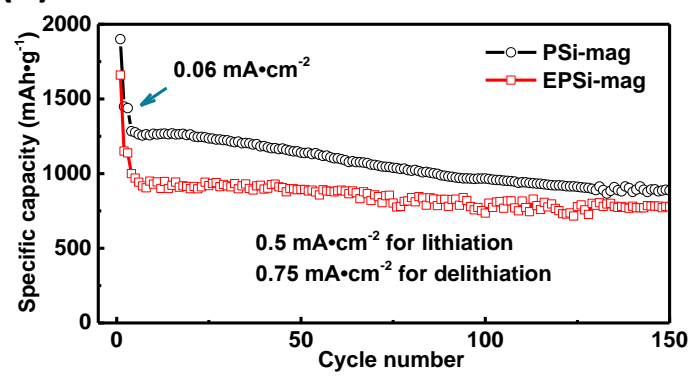


Figure 4

(a)

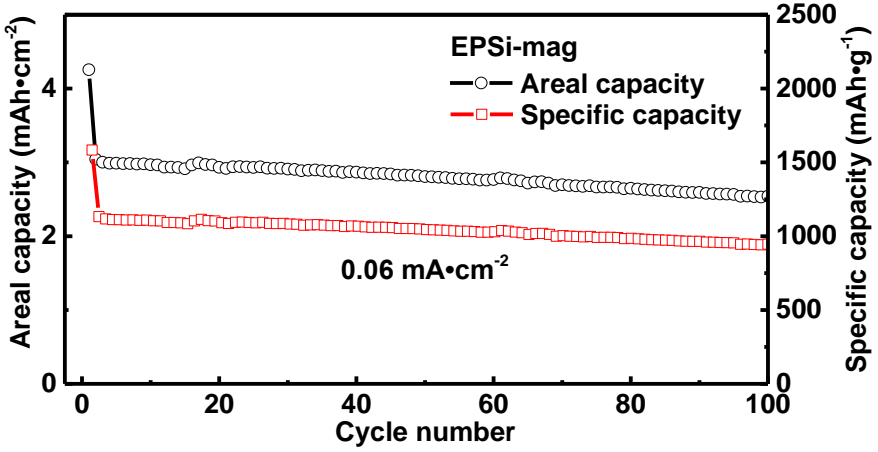

(b)

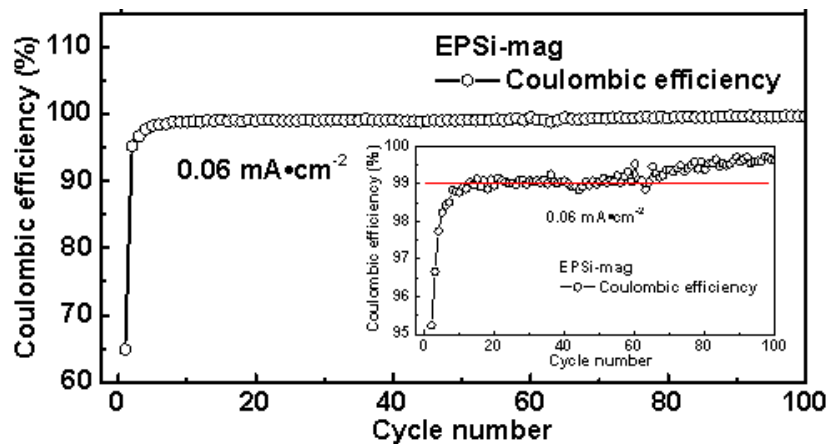

